\title{
DANÇA E MORADORES DE UM LAR PARA IDOSOS
}

Raphael Gonçalves de Oliveira

Bruna Maria Acedo Chiarion

Rozangela Verlengia

Rute Estanislava Tolocka

\section{Resumo}

Embora a população idosa tenha aumentado muito e vários estudos foram feitos sobre atividades físicas para ela, ainda é preciso estudos sobre idosos que vivem em instituições geriátricas. Assim, o objetivo deste estudo foi analisar bailes que ocorrem dentro de uma instituição geriátrica, em uma cidade do estado de São Paulo. Foi verificado que tais reuniões ajudam à inserção social, algumas pessoas da comunidade em volta da instituição vêm semanalmente para estas atividades, mas poucos moradores do lar tomam parte nelas. Boa parte destes moradores tem dificuldades de movimento, o que os limita na participação das atividades. Sugere-se que eles possam ter oportunidades para desenvolver habilidades motoras e capacidades físicas e que tais reuniões possam promover discussões sobre a vida em instituições geriátricas.

\section{Palavras-Chave}

Dança; Idoso; Desenvolvimento; Fisiologia.

\section{DANCES AND RESIDENTS OF A HOME FOR SENIOR}

Raphael Gonçalves de Oliveira

Bruna Maria Acedo Chiarion

Rozangela Verlengia

Rute Estanislava Tolocka

\begin{abstract}
Although the elderly population has increased a lot and many studies have been done about physical activities for them, we still need studies about elderly who lives in Geriatric institution. So, the purpose of this study was to analyze dance meetings that have happened inside of a geriatric institution in a city of Sao Paulo State. We found those meetings help the social insertion, some people from the community around came weekly for it, but just few residents take part on it,. Many of them have movement difficulty, which limits their participation in such activities. We suggested that they may have opportunities to develop their motor skills and physical performance as well those meetings may promote social discussion about the life at geriatrics institutions.
\end{abstract}

\section{Key-Words}

Dance; Elderly; Development; Physiology. 


\section{INTRODUÇÃO}

A população idosa no Brasil vem crescendo consideravelmente após 1980. De acordo com dados do IBGE (2000), naquele ano existiam aproximadamente 16 idosos para cada 100 crianças, em 2000, esse número passou para quase 30 idosos para 100 crianças. Os dados mostram que o maior crescimento relativo, foi do grupo com mais de 75 anos (49,3\%). Deste modo os idosos representam 8,6\% da população brasileira, sendo que destes, as mulheres são maioria, representando 55,1\% e para 2020 o número total de idosos no Brasil deve chegar a quase $13 \%$.

Envelhecer é uma das etapas no desenvolvimento do ser humano. Nesta fase da vida ocorrem várias mudanças. Estudos destacam alterações fisiológicas como, por exemplo, na massa óssea (BANDEIRA e CARVALHO, 2007), muscular (SILVA et al., 2006), articular (ZACARON et al. 2006), no aparelho circulatório e respiratório (LIBERBAN, 2007; ZAITUNE et al., 2006), no sistema adiposo (MARQUES, et al., 2005), no sistema endócrino (MENDONÇA; JORGE, 2002) e nervoso (FRIDMAN, 2004; MARQUES; KOZLOWSKI; MARQUES, 2004; RIBEIRO et al., 2004), dentre outros. Além dessas, as alterações na vida social do idoso também é apontada por vários estudos (JÓIA, RUIZ; DONALISIO; 2007; GUEDEA et al., 2006; LIMA-COSTA, MATOS; CAMARANO, 2006).

Todas essas alterações decorrentes do processo de envelhecimento podem ser amenizadas se a pessoa idosa dentre outros cuidados tiver um estilo de vida fisicamente ativo. Muitos estudos também apontam para os benefícios da atividade física nesta fase da vida (BENEDETTI; GONÇALVES; MOTA, 2007; MORAES et al., 2007; CAROMANO; IDE; KERBAUY, 2006), assim como os riscos do sedentarismo (SIQUEIRA et al., 2007; ZAITUNE et al., 2007; AMADO; ARRUDA, 2004).

Dentre as atividades que são realizadas por pessoas idosas, a dança parece ocupar um espaço importante, tendo em vista os tradicionais bailes que são realizados para terceira idade. Silva e Iwanowicz (1998) verificaram que os idosos ao se engajarem em programas de dança parecem estar à procura de diversão e amizades, e querem aprender a dançar para ter o prazer de realizar atividades de danças dentro de sua comunidade, não apenas com seus pares em programas para idosos, mas também para ser capaz de dançar com seus familiares.

Tal atividade mostra-se interessante, uma vez que pode auxiliar na manutenção dos aspectos físicos, cognitivos e sociais de idosos. Primeiro por fornecer todos os estímulos para a atenuação dos efeitos bioquímicos relacionados à idade que ocorrem no músculo esquelético e assim auxiliar na manutenção da 
autonomia física. Segundo, por promover oportunidade para execução de movimentos que estão fora do repertório motor diário, se configurando em estímulo cognitivo interessante. Por fim, tal atividade proporciona convívio social importante para manutenção das inter-relações sociais nos idosos. Assim, a dança pode contribuir não só para a manutenção, mas também para o desenvolvimento de aspectos relacionados à qualidade de vida dos idosos.

$\mathrm{Na}$ dança podem-se utilizar ritmos variados, com passos fáceis ou mais complexos. O objetivo mais importante é que essas técnicas sejam utilizadas de forma que contribuam à recuperação dos movimentos básicos do cotidiano do idoso, e para que ele possa adquirir um bem estar físico, psíquico e social. Tais características dessa modalidade permitem a variação nas intensidades da atividade, o que permite ser modulada para estimular vias metabólicas específicas, bem como a complexidade dos exercícios pode ser alterada com o intuito de estimular a cognição (FIGUEIREDO, 1997).

A participação, em longo prazo, em atividades de dança, propicia aumento da força muscular e do equilíbrio, fatores que notadamente são essenciais na prevenção de quedas (SHIGEMATSU et al., 2002) e favorecem a independência do idoso na comunidade (JUDGE, 2003) e melhoram a imagem corporal (LEWIS; SCANNELL, 1995).

Atualmente é grande o número de estudos acerca do envelhecimento humano, porém, quando se trata de idosos institucionalizados, existem ainda poucos trabalhos. Estudar e tentar entender o idoso que se encontra nessas condições se torna importante tendo em vista o crescente número destas entidades e consequentemente o aumento no número de pessoas institucionalizadas.

De acordo com Gorzoni; Pires (2006) as instituições geriátricas têm por objetivo atender integralmente a pessoa idosa, dependente ou não, que não tenha condições familiares e domiciliares de permanecer em sua comunidade de origem. Segundo Silva et al. (2007), o idoso asilado na maioria das vezes perde contato com o mundo ao qual vivia antes da institucionalização, entregando-se a rotina da instituição, desligando-se da sua história de vida e muitas vezes perde também sua privacidade.

Assim a dança pode propiciar desenvolvimento físico e amenizar as perdas decorrentes do processo de institucionalização, funcionando como um veículo para aproximação e convívio social, no entanto pouco se sabe sobre a participação de idosos institucionalizados em atividades de dança. 


\section{OBJETIVOS}

Observar atividades de dança dentro de uma instituição para idosos, levantando subsídios para a implantação de novos programas de dança para esta parcela da população.

\section{METODOLOGIA}

A pesquisa caracteriza-se como descritiva, de análise qualitativa e de campo. Para a coleta de dados, foram realizadas observações participativas, com registro em diário de campo. O método utilizado para as observações foi a de observador como participante. Esta técnica tem por objetivo estar em contato direto com o grupo estudado em que os objetivos do estudo são revelados, podendo-se deste modo pedir a cooperação e o acesso a informações deste grupo, conforme os critérios propostos por Lüdke e André (1986).

Foram feitas onze observações nos bailes realizados às quintas-feiras no período da tarde em um Lar para idosos de uma cidade do interior de São Paulo. O número de pessoas observadas foi aleatório, tendo em vista que o grupo já era previamente constituído.

Dentre estas pessoas estão idosos moradores do Lar, tanto dos pavilhões quanto das casas e pessoas não moradoras do Lar, mas que dele participam com freqüência. Os sujeitos assinaram termo de consentimento livre e esclarecido para efetivação do estudo e a instituição concedeu autorização para isto. O estudo foi aprovado pelo conselho de ética em pesquisas.

\section{RESULTADOS E DISCUSSÃO}

O baile é realizado no refeitório da instituição, e ocorre semanalmente em um espaço de aproximadamente $200 \mathrm{~m}^{2}$. Os idosos que tocam os instrumentos não moram na instituição e realizam este trabalho de forma voluntária. A pessoa que toca sanfona é o responsável pelo grupo e realiza este evento desde o seu primeiro dia a mais de 27 anos atrás. Os instrumentos utilizados são: violão, surdo, pandeiro, sanfona e triângulo. Os ritmos que são tocados lembram as músicas mais antigas, e dentre eles podemos citar: a valsa, o samba, o forró, arrastapé, vanerão, xote, bolero, rancheira, dentre outros.

As danças duram aproximadamente 5 minutos e todas as vezes que terminam, todos os casais que estavam dançando se sentam e após 30 segundos aproximadamente uma nova música começa a ser tocada e novos casais são formados. No momento da dança, os casais giram em sentido anti-horário, fazendo o formato de um círculo. Há também intervalos maiores para que os músicos possam se alimentar. Como Figueiredo 
(1997) esta modulação das atividades auxiliam a estimular vias metabólicas específicas, aumentando a chance de participação das pessoas idosas nas atividades.

O número de idosos que participam deste baile varia de 49 pessoas no dia e horário que esteve mais vazio, até 104 no dia e horário em que esteve mais cheio (os dias mais cheios contaram com a participação de jovens universitários que vieram realizar um estágio). O número máximo de casais que se pode observar dançando foram 18. Normalmente os casais que efetivamente dançam são compostos por idosos que não moram na instituição. Os idosos institucionalizados ficam na sua grande maioria observando e na expectativa de que alguém os convide para dançar. Estes idosos são caracterizados pela debilidade dos movimentos.

E curioso observar que são quase sempre as mesmas pessoas que dançam, trocando somente de par e também quase sempre as mesmas que somente observam, constituindo claramente dois grupos distintos. Uma alternativa para tentar resolver essa diferença existente nos bailes entre o grupo de idosos que demonstram mais habilidades quando dançam e o grupo de idosos que não possuem habilidade, é proporcionar um ambiente em que idosos do segundo grupo possam desenvolver recursos para a dança. No estudo de Leal e Haas (2006), as idosas que se engajaram num programa de dança para a terceira idade, superaram as dificuldades iniciais em alguns meses e obtiveram não somente sucessos na aprendizagem da dança, como também melhoraram em outros aspectos.

Dentre os participantes do baile que convidam moradores do Lar para dançar, estão à neta de uma moradora do Lar que acompanha a avó e uma senhora que trabalha como voluntária, assim são raras as pessoas que convidam os moradores da instituição.

$\mathrm{Na}$ maioria das vezes que uma destas duas pessoas convidam os moradores do lar para dançar, estes vão em fila de três ou quatro pessoas, andando pelo salão, girando no mesmo sentido que os demais. Uma pessoa usuária de cadeira de rodas é empurrada na frente pela voluntária e outros dois ou três idosos vão segurando na cintura do que está à frente como se fosse um "trenzinho". Antes que a música acabe estes idosos são colocados de volta nas cadeiras que estavam sentados e outros são convidados para dançar em seu lugar. 
Esta forma de participação, embora seja limitada pela falta de recursos para dançar, auxilia na interação social, aumentando a força da participação, que passa da observação à participação conjunta. A maioria das pessoas que residem na instituição e participam deste baile, são usuárias de cadeira de rodas, andador, bengala, ou possuem alguma deficiência física e/ou mental. No início do baile são conduzidas até o salão por acompanhantes, voluntários ou estagiários e no final são levadas novamente por estas pessoas até seus pavilhões.

Segundo Carmo (2005, p. 45), para que as pessoas caracterizadas como as diferentes dentro de um grupo ou sociedade sejam incluídas, será preciso "desenvolver nas mentes das pessoas a capacidade de colaboração de uns com os outros, visando ao beneficio de todos", em que prevaleça a unidade dentro da diversidade em detrimento de apelos sentimentais ou da negação das identidades. Assim seria necessário que fossem oferecidos aos idosos moradores do lar, oportunidades para desenvolver recursos que os ajudassem a atrair outras pessoas para dançar com eles, que vão deste técnicas simples de dança ao incentivo da utilização de habilidades psico-sociais.

Como estas pessoas possuem alterações de marcha, seria importante a presença de um profissional que pudesse oferecer treinamento especializado aos idosos para utilização das próteses e órteses, aumentando as possibilidades de participação das mesmas. Por exemplo, fornecer técnicas de manejo da cadeira de rodas, tanto para o idoso quanto para quem quiser auxiliá-lo a se deslocar, poderia trazer novas formas de participação na dança, que não fosse apenas empurrar/ser empurrado pelo espaço, mas que oferecesse uma nova possibilidade de dançar e até de questionar a estética vigente, como tem sido feito com a dança contemporânea, que incluiu a dança em cadeira de rodas como modalidade e tem contribuído para mudança do signo e do significado da cadeira de rodas (TOLOCKA; FERREIRA, 2006).

Ao contrário dos moradores do Lar, as pessoas que vêm de fora apresentam na sua maioria, alguma habilidade para a dança, o que contribui para que sejam mais vezes convidadas para dançar. Esses idosos frequentemente dançam entre si e têm parceiros certos. Ter habilidade para a dança parece ser um recurso importante para ser convidado ou ter sucesso ao convidar um parceiro para dançar.

As pessoas possuem características que podem favorecer (recursos ativos) ou não (recursos passivos) o seu desenvolvimento (COPETTI; KREBS, 2004). Assim como os ambientes no qual elas estão inseridas são capazes de influenciá-las (BRONFENBRENNER, 1996). 
Para Bronfenbrenner; Morris (1999) os recursos fazem parte dos atributos de uma pessoa em desenvolvimento, e são ativos ou passivos biopsicológicos. As condições passivas fazem com que o desenvolvimento seja limitado ou rompido, como por exemplo, no caso de defeitos genéticos, baixo peso, dificuldades físicas, doenças severas, danos cerebrais, dentre outros. As condições ativas favorecem o desenvolvimento da pessoa (ter habilidades, conhecimentos, destrezas e experiências pessoais).

Para contrabalancear as limitações do desenvolvimento impostas pelas alterações decorrentes da idade ou da aquisição de patologias é necessário buscar formas diferenciadas de movimento, que permitam responder satisfatoriamente as demandas ambientais, o que a dança pode propiciar, já que estimula a criação de movimento e possibilita a transmissão de mensagens.

Na maioria das vezes são os homens que convidam as mulheres para dançar, porém, algumas vezes podese ver mulheres convidando também. Alguns casais no momento da dança são formados por duas mulheres, mas na maioria são formados por um homem e uma mulher. Apenas duas vezes pode-se observar uma pessoa dançando sozinha.

O fato de ser observado durante algumas músicas casais do mesmo sexo dançando (mulher com mulher), pode ser justificado pelo fato das mulheres serem maioria durante os bailes, representando quase o dobro do número de homens. Respeitar a cultura de origem, como por exemplo, estilo da dança e hábitos sociais relativos a gênero, são questões que devem ser levadas em consideração na criação de um programa de dança para a terceira idade.

Uma outra questão importante a ser discutida, diz respeito ao convívio social de pessoas institucionalizadas. Araújo, Coutinho e Santos (2006) compararam idosos institucionalizados com idosos que participam de grupos de convivência (GC), e chegaram à conclusão de que por um lado, os idosos que participam dos GC, vivenciam atividades que envolvem aspectos sócio-recreativos valorizando a promoção da saúde e o exercício da cidadania, e por outro lado, os idosos asilados, devido à institucionalização, vivem num confinamento sócio-afetivo. No caso dos idosos que moram no Lar estudado, foi dada a oportunidade para que participem de uma atividade em que podem se relacionar socialmente com pessoas do próprio Lar e pessoas que não são moradoras do mesmo. Estar no baile, ainda que apenas observando é uma forma ativa de participar e aproximar as pessoas, embora fosse mais efetivo se todos pudessem ter a escolha de dançar ou não, sem ser por falta de possibilidades físicas. 
Outro fato curioso, e que desperta o interesse para futuras investigações, foi a constatação que a grande maioria dos moradores deste Lar não participa destes bailes. Saber o porquê destes idosos não irem ao baile, pode ser importante para delinear fatores que podem favorecer a participação destas pessoas, auxiliando no delineamento de propostas de atividades de dança para esta parcela da população.

\section{CONSIDERAÇÕES FINAIS}

Neste estudo, ficou clara a necessidade de proporcionar ambientes para que o idoso, principalmente os institucionalizados, possam vir a desenvolver recursos pessoais que possibilitem a participação social. Dentre estes, estão os recursos que podem ser trabalhados durante atividades de dança, tais como desenvolvimento de habilidades motoras de manejo de uma cadeira de rodas, aumento de capacidades físicas, incentivo a habilidades psico-sociais. Estes bailes poderiam ser utilizados como espaço para discussão da situação social da pessoa institucionalizada, aproximando a comunidade das necessidades desta parcela da população, substituindo apelos sentimentais por conhecimento das diferenças individuais, propiciando também atividades que incentivassem a autonomia e o exercício da plena cidadania.

\section{REFERÊNCIAS}

AMADO, T. C. F.; ARRUDA, I. K. G. Hipertensão arterial no idoso e fatores de risco associados. Revista Brasileira de Nutrição Clínica. São Paulo: v.19, n.2, p.94-99, 2004.

ARAÚJO, L. F.; COUTINHO, M. P. L.; SANTOS, M. F. S. O idoso nas instituições gerontológicas: Um estudo na perspectiva das representações sociais. Psicologia e Sociedade, Porto Alegre: v. 18, n. 2, p.89-98, maio/ago, 2006.

BANDEIRA, F.; CARVALHO, E. F. Prevalência de osteoporose e fraturas vertebrais em mulheres na pós-menopausa atendidas em serviços de referência. Revista Brasileira de Epidemiologia. São Paulo: v.10, n.1, p.86-98, mar. 2007.

BENEDETTI, T. R. B.; GONÇALVES, L. H. T; MOTA, J. A. P. S. Uma proposta de política pública de atividade física para idosos. Texto e Contexto: Enfermagem, Florianópolis, v.16, n.3, p.387-398, jul./set, 2007.

BRONFENBRENNER, U. A ecologia do desenvolvimento humano: experimentos naturais $e$ planejados. Porto Alegre: Artes Médicas, 1996.

; MORRIS, P. A. The ecology of developmental process. In: PEDRO, J. G. (Ed.). Stress and violence in childhood and youth. Lisboa: Univ. Lisboa, 1999. p. 21-95. 
CARMO, A. A. Diversidade humana e educação. In: FERREIRA, E. L. (Org.). Dança artística e esportiva para pessoas com deficiência: multiplicidade, complexidade e maleabilidade corporal. Juiz de Fora: CBDCR, 2005.

CAROMANO, F. A.; IDE, M. R.; KERBAUY, R. R. Manutenção na prática de exercícios por idosos. Revista do Departamento de Psicologia. Niterói, v.18, n.2. p.177-192, jul./dez. 2006.

COPETTI, F.; KREBS, R. J. As propriedades da pessoa na perspectiva do paradigma bioecológico. In: KOLLER, S. H. (Org.). Ecologia do desenvolvimento humano: pesquisa e intervenção no Brasil. São Paulo: Casa do Psicólogo, 2004.

FIGUEIREDO, V. M. C. Olhar para o corpo que dança: um sentido para pessoa portadora de deficiência visual. 1997. Dissertação (Mestrado) - Universidade Estadual de Campinas, Campinas, 1997. FRIDMAN, C. et al. Alterações genéticas na doença de Alzheimer. Revista de Psiquiatria Clínica, São Paulo, v.31, n.1, p.19-25, 2004.

GORZONI, M. L.; PIRES, S. L. Aspectos clínicos da demência senil em instituições asilares. Revista de Psiquiatria Clínica. São Paulo, v. 33, n.1, p. 18-23, 2006.

GUEDEA, M. T. D. et al. Relação do bem-estar subjetivo, estratégias de enfrentamento e apoio social em idosos. Psicologia Reflexão e Crítica, Porto Alegre, v. 19, n. 2, p.301-308, 2006.

IBGE. Perfil dos idosos responsáveis pelos domicílios: dados referentes ao censo de 2000. Disponível em: http://www.ibge.gov.br. Acesso em: 04 ago. 2007.

JOIA, L. C.; RUIZ, T.; DONALISIO, M. R. Condições associadas ao grau de satisfação com a vida entre a população de idosos. Revista de Saúde Pública, São Paulo, v. 41, n. 1, p.131-138, fev. 2007.

JUDGE. J. Balance training to maintain mobility and prevent disability. American Journal Preventive Medicine. v. 25, n. 3, p.150-156, oct. 2003.

LEAL, I. F.; HAAS, A. N. O significado da dança na terceira idade. Revista Brasileira de Ciências do Envelhecimento Humano, . Passo Fundo, v.3, n.1, p.64-71, jan./jun. 2006.

LEWIS, R. N.; SCANNELL, E. D. Relationship of body image and creative dance movement. Percept Mot Skills, v. 81, n.1, p.155-160, aug995.

LIBERMAN, A. Aspectos epidemiológicos e o impacto clínico da hipertensão no indivíduo idoso. Revista Brasileira de Hipertensão, Ribeirão Preto, v.14, n.1, p.17- 20, jan./mar, 2007.

LIMA-COSTA, M. F. L.; MATOS, D. L.; CAMARANO, A. A. Evolução das desigualdades sociais em saúde entre idosos e adultos brasileiros: um estudo baseado na Pesquisa Nacional por Amostra de Domicílios (PNAD 1998, 2003). Ciência e Saúde Coletiva, Rio de Janeiro, v. 11, n.4, p. 
941-950, out./dez, 2006.

LÜDKE, M.; ANDRÉ, M. E. D. A. Pesquisa em educação: abordagens qualitativas. São Paulo: EPU, 1986.

MARQUES, A. C. O.; KOZLOWSKI, L.; MARQUES, J. M. Reabilitação auditiva no idoso. Revista Brasileira de Otorrinolaringologia, São Paulo, v. 70, n. 6, p. 806-811, nov./dez. 2004.

MARQUES, A. P. O. et al. Prevalência de obesidade e fatores associados em mulheres idosas. Arquivos Brasileiros de Endocrinologia e Metabologia, São Paulo, v. 49, n. 3, p.441-448, jun. 2005. MENDONÇA, S. C. L.; JORGE, P. T. Estudo da função tiroideana em uma população com mais de 50 anos. Arquivos Brasileiros de Endocrinologia e Metabologia, São Paulo, v. 46, n. 5, p. 557-565, out. 2002.

MORAES, H. et al. O exercício físico no tratamento da depressão em idosos: revisão sistemática. Revista de Psiquiatria do Rio Grande do Sul. Porto Alegre, v. 29, n. 1, p. 70-79, jan./abr. 2007.

RIBEIRO, J. E. C. et al. Associação entre aspectos depressivos e déficit visual causado por catarata em pacientes idosos. Arquivos Brasileiros de Oftalmologia, São Paulo, v. 67, n. 5, p.795-799, set/out. 2004.

SHIGEMATSU, R. et al. Dance - based aerobic exercise may improve indices of falling risk in older women. Age and Ageing, v. 31, n. 4, p. 261-266, jul. 2002.

SILVA, C. A. et al. Vivendo após a morte de amigos: história oral de idosos. Texto e Contexto: enfermagem, Florianópolis, v. 16, n. 1, p. 97-104, jan./mar. 2007.

SILVA, T. A. A. et al. Sarcopenia associada ao envelhecimento: aspectos etiológicos e opções terapêuticas. Revista Brasileira de Reumatologia, São Paulo, v. 46, n. 6, p. 391-397, nov/dez. 2006.

SILVA, V. M. T.; IWANOWICZ, J. B. A importância dos programas de "Universidade na Terceira Idade" para os idosos que deles participam. In: CONGRESSO MUNDIAL DE LAZER E $10^{\circ}$ ENCONTRO NACIONAL DE RECREAÇÃO E LAZER, 5. Anais... São Paulo, 1998.

SIQUEIRA, F. V. et al. Prevalência de quedas em idosos e fatores associados. Revista de Saúde Pública. São Paulo: v.41, n.5, p.749-756, out, 2007.

TOLOCKA, R. E.; FERREIRA, E. L. Dança em cadeira de rodas: uma possibilidade de transcendência. In: RODRIGUES, D. (Org.). Atividade motora adaptada: a alegria do corpo. São Paulo: Summus, 2006. ZACARON, K. A. M.; et al. Nivel de atividade física, dor e edema e suas relações com a disfunção muscular do joelho de idosos com osteoartrite. Revista Brasileira de Fisioterapia, São Carlos, v. 10, n. 3, p. 279-284, jul./set. 2006. 
ZAITUNE, M. P. A. et al. Fatores associados ao sedentarismo no lazer em idosos. Campinas. Cadernos de Saúde Pública, Rio de Janeiro, v. 23, n. 6, p.1329-1338, jun. 2007.

Hipertensão arterial em idosos: prevalência, fatores associados e práticas de controle no municipio de Campinas, São Paulo, Brasil. Cadernos de Saúde Pública, Rio de Janeiro, v. 22, n. 2, p. 285-294, fev. 2006. 
Raphael Gonçalves de Oliveira

Educação Física pela Universidade Metodista de Piracicaba.

Bruna Maria Acedo Chiarion

Universidade Metodista de Piracicaba.

\section{Rozangela Verlengia}

Educação Física- Universidade Metodista de Piracicaba.

\section{Rute Estanislava Tolocka}

Universidade Metodista de Piracicaba.

\section{Referência do artigo:}

ABNT

OLIVEIRA, R. G. et al. Dança e moradores de um lar para idosos. Conexões, v. 6, p. 498-509, 2008.

\section{APA}

Oliveira, R. G., Chiarion, B. M. A., Verlengia, R., \& Tolocka, R. E. (2008) Dança e moradores de um lar para idosos. Conexões, 6, 498-509.

\section{VANCOUVER}

Oliveira RG, Chiarion BMA, Verlengia R, Tolocka RE. Dança e moradores de um lar para idosos. Conexões, 2008; 6: 498-509. 